\title{
Recent advances in the reconstruction of cranio-maxillofacial defects using computer-aided design/computer-aided manufacturing
}

\author{
Ji-hyeon Oh(D)
}

\begin{abstract}
With the development of computer-aided design/computer-aided manufacturing (CAD/CAM) technology, it has been possible to reconstruct the cranio-maxillofacial defect with more accurate preoperative planning, precise patient-specific implants (PSIs), and shorter operation times. The manufacturing processes include subtractive manufacturing and additive manufacturing and should be selected in consideration of the material type, available technology, post-processing, accuracy, lead time, properties, and surface quality. Materials such as titanium, polyethylene, polyetheretherketone (PEEK), hydroxyapatite (HA), poly-DL-lactic acid (PDLLA), polylactide-co-glycolide acid (PLGA), and calcium phosphate are used. Design methods for the reconstruction of cranio-maxillofacial defects include the use of a pre-operative model printed with pre-operative data, printing a cutting guide or template after virtual surgery, a model after virtual surgery printed with reconstructed data using a mirror image, and manufacturing PSIs by directly obtaining PSI data after reconstruction using a mirror image. By selecting the appropriate design method, manufacturing process, and implant material according to the case, it is possible to obtain a more accurate surgical procedure, reduced operation time, the prevention of various complications that can occur using the traditional method, and predictive results compared to the traditional method.
\end{abstract}

Keywords: Computer-aided design/computer-aided manufacturing, Three-dimensional imaging, Cranio-maxillofacial defect, Reconstructive surgical procedures, Custom implant, Patient-specific implant

\section{Introduction}

The reconstruction of complex cranio-maxillofacial defects is challenging due to the unique anatomy, the presence of a vital structure, and the variety of deficits $[1,2]$. The reconstruction of congenital or acquired cranio-maxillofacial defects due to congenital abnormalities, post-trauma, tumor resection, and infection requires both functional and esthetic considerations $[3,4]$.

Computer-aided design $(\mathrm{CAD})$ is the process of creating, modifying, analyzing, or optimizing a design using computer system. Computer-aided manufacturing (CAM) is the process of planning, managing, or controlling manufacturing using computer system [5].

Correspondence: haruna348@naver.com

Department of Oral and MaxilloFacial Surgery, Dental Hospital,

Gangneung-Wonju National University, Gangneung, South Korea
In the early 1960s, CAD was developed in the aircraft and automotive industries, and in the late 1960s, the supply of computer system for CAD was specialized [6]. In the late 1980s, computer-controlled milling was used to produce prosthesis using three-dimensional (3D) imaging data in computed tomography $(\mathrm{CT})$ [7]. With the development of CAD/CAM technology, there have been increasing cases of restructuring cranio-maxillofacial defects to improve appearance and function with more accurate surgery and shorter operation times [8]. With CAD/CAM software, accurate pre-operative planning can be established, and surgeons can perform virtual ablation, plan osteotomy and reconstruction procedures, or create patient-specific implants (PSIs) [3, 4, 9] (Fig. 1).

The advantages of CAD/CAM technology include improved accuracy of esthetic results, restoration of large and geometrically complex anatomical defects, reduction 


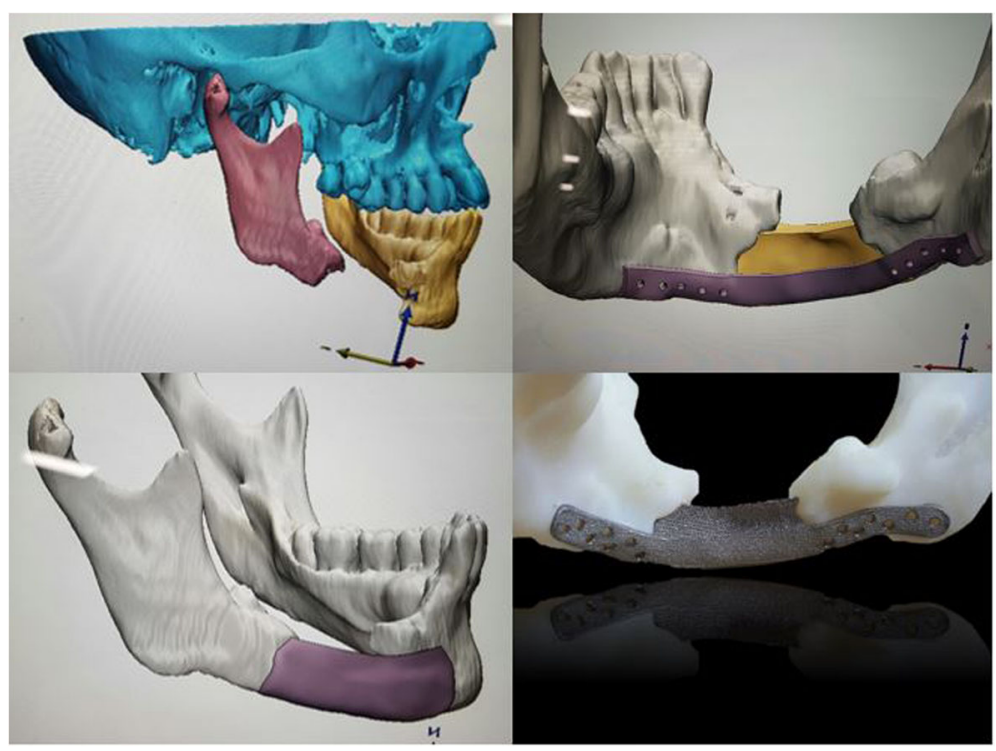

Fig. 1 Pre-operative diagnosis, virtual surgery, and creation of patient-specific implants using CAD/CAM software

of operative times, more accurate fitting of implants, overcoming the disadvantages of autogenous bone grafts, and performing resection and reconstruction in one step $[10,11]$. The $3 \mathrm{D}$ printing technique in the craniomaxillofacial area surgery includes contour models that are accurate replicas of patient-specific anatomy, guides that are patient-specific templates that guide precise cutting and drilling, splints defined as the replica of the virtual post-operative position of the patient structure, and implants defined as three-dimensionally printed objects that are directly implanted in the patients $[12,13]$.

In this paper, we will discuss the manufacturing processes using CAD/CAM, implant materials, the workflow reconstructing the cranio-maxillofacial defects, and future directions of development.

\section{Review}

\section{The manufacturing processes}

The manufacturing processes include subtractive manufacturing, which cuts off a piece of material to form the final shape, and additive manufacturing, which builds up the material by stacking [8]. Subtractive manufacturing, the traditional machining technique has the disadvantage in that it is difficult to make complicated shapes by computer numerical control $(\mathrm{CNC})$ milling and there is a lot of material waste [14].

Additive manufacturing, known as rapid prototyping or 3D printing, has the advantage of being very sophisticated, with less material waste, faster production times, and the ability to produce complex structures [8]. There are several additive manufacturing processes, including binder jetting (BJG), direct metal laser sintering (DMLS), electron beam melting (EBM), laser engineered net shaping (LENS), and fused deposition modeling (FDM) [15-17]. Figure 2 is a simplified schematic of the manufacturing processes described in this paper.

BJG generally uses two materials: a powder material from which the part is made and a binder material that bonds between the powder materials (Fig. 3). It has the advantage that parts can be produced without support structures, but it has the disadvantage that postprocessing takes more time than actual printing, resulting in a significant increase in cost. In addition, the parts have rough microstructure and lower mechanical properties than those produced by selective laser melting (SLM) or EBM because of the possibility of porosity and heat treatment [16].

DMLS, referred to using the terms SLM or selective laser sintering (SLS), uses a high-powered optic laser to fuse the metal powder to solid components based on a 3D CAD file and, similar to EBM, is built layer by layer [17]. Similar to BJG, a powder bed is used to create a 3D object. However, instead of using a spray solution, a laser is used to tie the powder particles together, and the laser is instructed to draw a specific pattern on the surface of the powder bed during the printing process [18]. When the first layer is completed, the roller sprinkles a new layer of powder on top of the previous layer, pushes it flat, and then uses the laser to make the object layer by layer [19] (Fig. 4). DMLS have many advantages and disadvantages [16]. The advantages include the use of a wide range of materials, improved functionality, relatively low cost, and the production of ready-to-use near-netshaped components. On the other hand, the disadvantages include relatively slow processes, size limitations, high power consumption, and high initial cost. In addition, the 


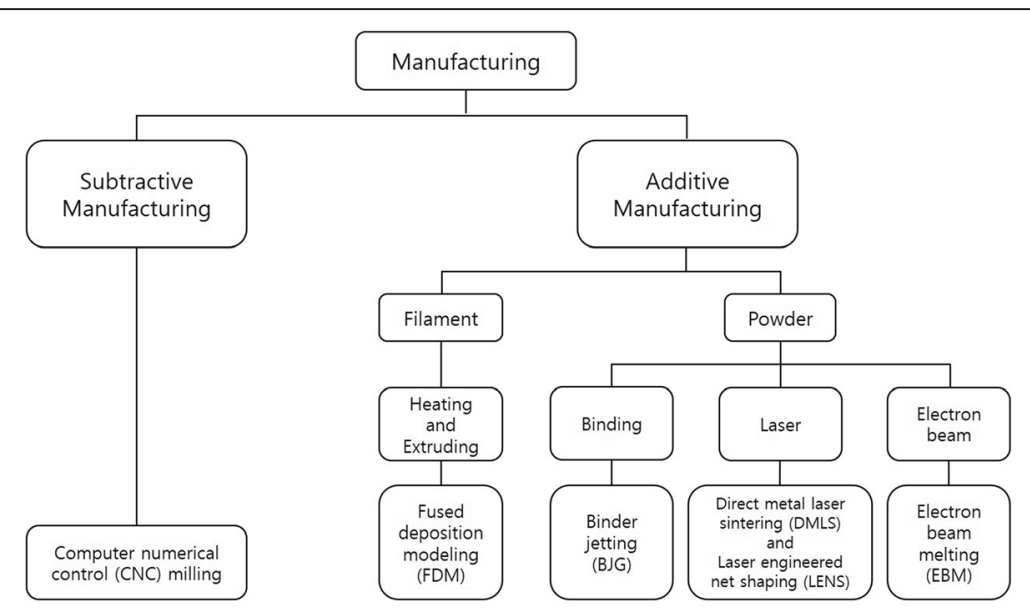

Fig. 2 Schematic of the manufacturing processes

handling of the powder is tricky, the produced parts can have rough surfaces, and the brittle materials that cannot accommodate high internal stress during the manufacturing process can cause cracking of the parts.

EBM is very similar to DMLS, but there is a slight difference in that the parts are fabricated by melting the metal powder in a layer using an electron beam [17] (Fig. 5). In EBM, the cooling rate can be greatly reduced by increasing the temperature of the powder bed. Unlike DMLS, EBM has the ability to treat brittle materials that cannot be processed by DMLS because it slowly cools, avoiding solidification cracking of brittle materials. However, it takes longer than DMLS and requires sufficient cooling time before removing parts from the substrate plate because the electron beams are used many times in the layers [16].

Similar to EBM and DMLS, LENS is used to fabricate metal parts directly from CAD solid models and has the difference in that metal powders are injected into the molten pool generated by the condensed high-power laser beam [17]. The molten material line rapidly solidifies as the laser beam retreats, and after each layer is formed, the

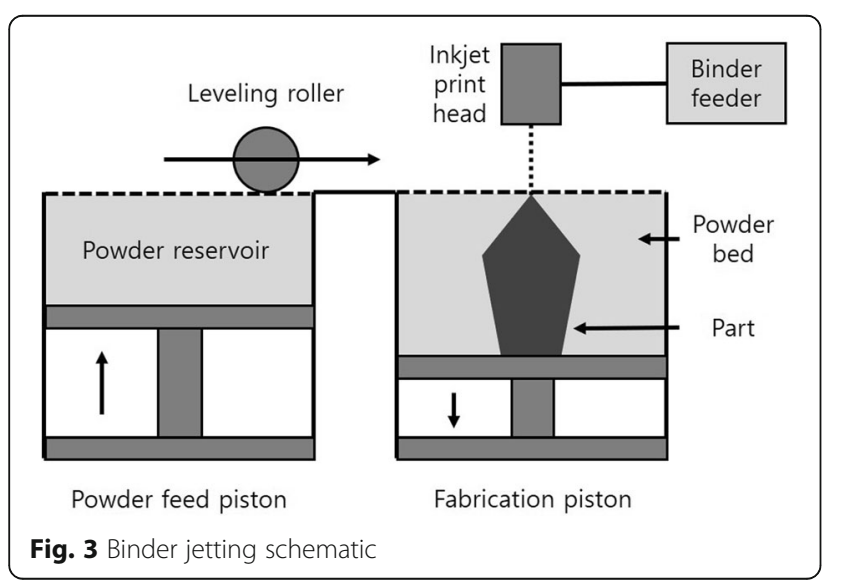

laser head advances by one-layer thickness together with the powder feed nozzle, and a subsequent layer is created. This is repeated several times until the entire object displayed in the 3D CAD model is created [20] (Fig. 6).

FDM is generally carried out with a polymer melted in a printer nozzle and arranged layer by layer. The material is melted and deposited at a defined location on the printing layer, and after the first layer is completed, the distance between the printing bed and the extruder nozzle is increased and the second layer is printed on the first layer [21] (Fig. 7).

There are various kinds of manufacturing processes. The manufacturing process should be selected with consideration of the material type, available technology, post-processing, accuracy, lead time, properties, and surface quality [16].

\section{Implant materials}

The ideal material is biocompatible, easy to shape, high strength, non-toxic, inexpensive, durable, radiolucent,

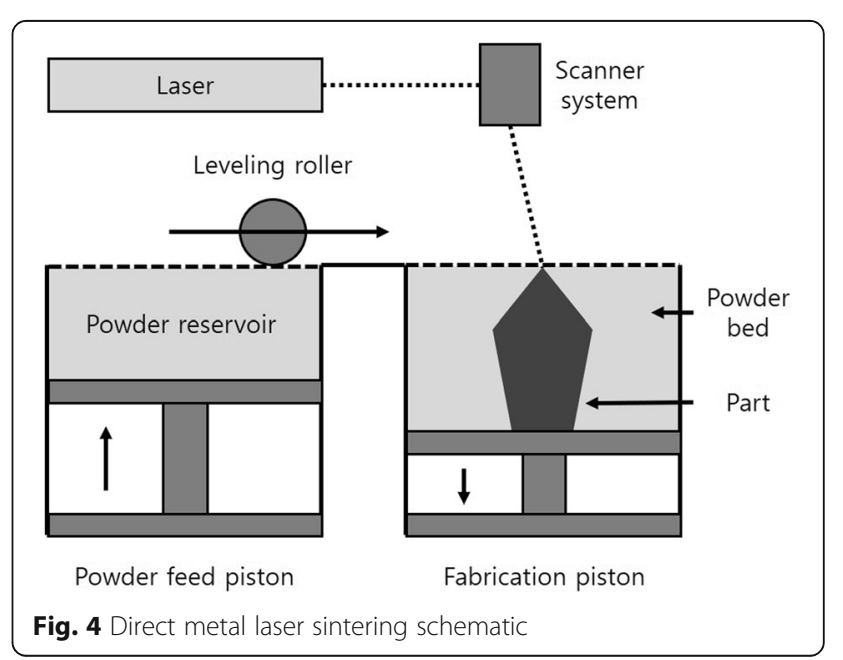




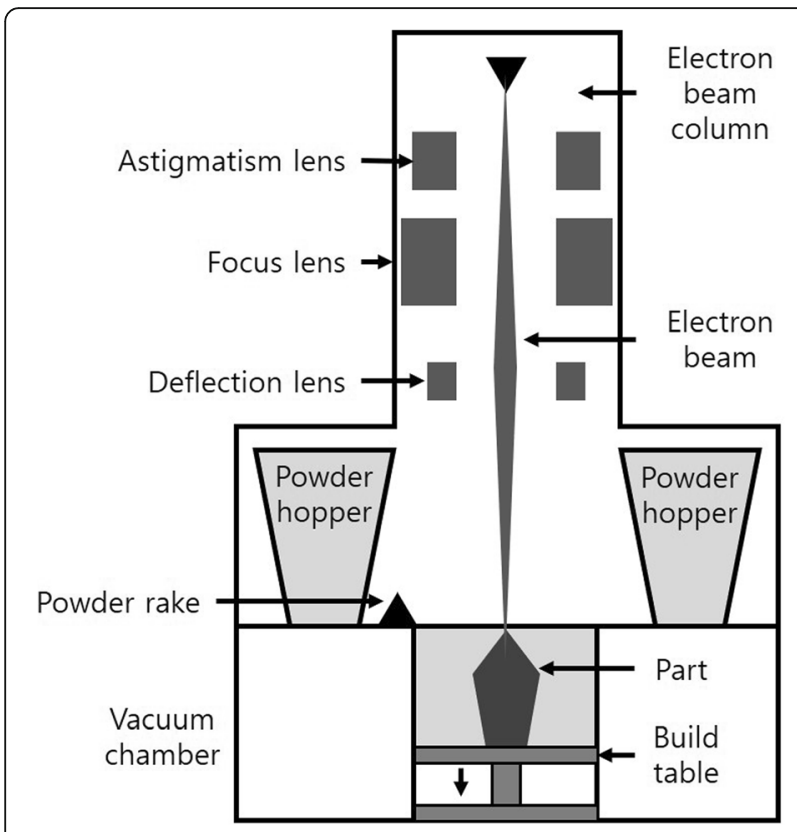

Fig. 5 Electron beam melting schematic

and lightweight $[8,22]$. However, no material satisfies these conditions [22-24]. Materials include non-resorbable materials such as titanium, polyethylene, polyether ether ketone (PEEK), and hydroxyapatite (HA) and absorbable materials such as poly-DL-lactic acid (PDLLA), polylactideco-glycolide acid (PLGA), and calcium phosphate.

Titanium is the metal of choice for manufacturing implants. It has the advantages of high strength, biocompatibility, lightweight, corrosion resistance, and the potential for osseointegration $[8,25,26]$. However, it has the disadvantage of causing scatter artifacts in CT scans [27].

Polyethylene includes porous polyethylene (PPE) and ultra-high molecular weight polyethylene (UHMW-PE). PPE such as Medpor (Pufex Surgical Inc., College Park,

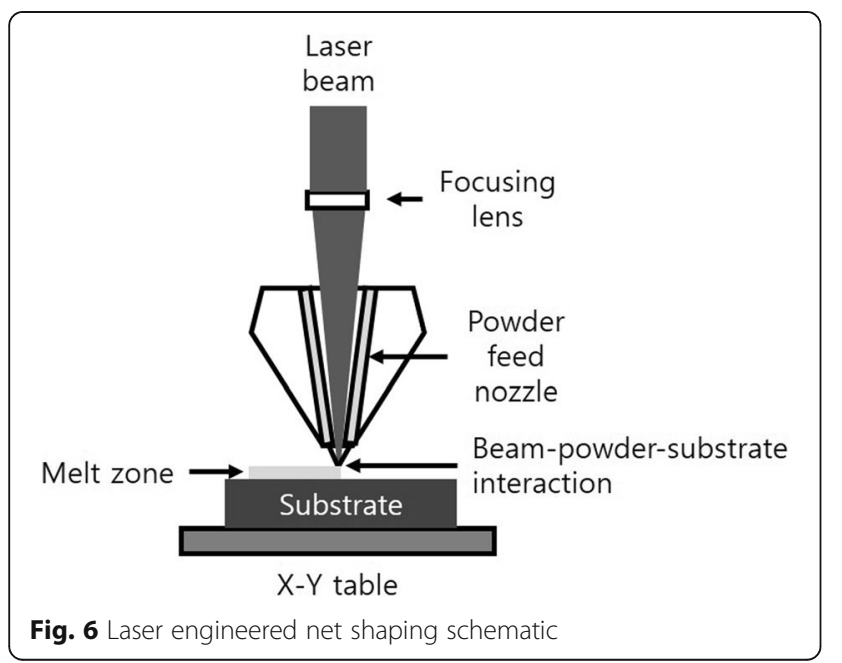

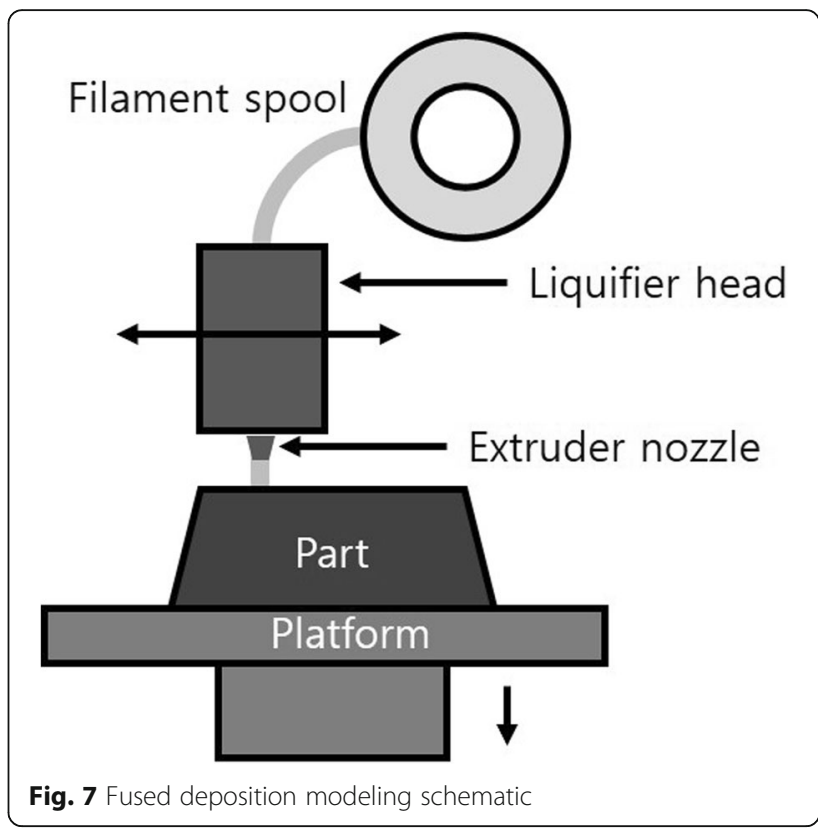

GA, USA) was used for reconstruction of the orbital floor and augmentation of the facial area [28]. PPE is very stable and easy to shape and has tissue ingrowth through its pores $[29,30]$. However, there is a possibility of infection [28]. UHMW-PE was used for reconstruction of orbit or temporomandibular joint by making PSIs using CAD/CAM [31, 32]. Because of a solid structure, UHMW-PE can have a lower infection rate than PPE [32]. Polyethylene has the advantage of not producing artifact because of radiolucency in $\mathrm{CT}$, but it also has a disadvantage that it is difficult to control implant position after surgery $[3,32]$.

PEEK was used to reconstruct various craniofacial bone defects including cranioplasty [23, 33]. PEEK has similar strength and elasticity to bone and is easy to modify [34]. It is radiolucent in CT and offers more comfort to patients, with lower thermal conductivity and lighter weight than titanium. However, it had reports of infection and foreign body reaction [27].

HA is used as a biocompatible scaffolding material for bone tissue engineering [35]. It is osteoconductive and non-resorbable and shows tissue in-growth in the presence of pores, with a strong capacity to bind both hard and soft tissues [36]. Pure HA is low in viscosity and difficult to make complex shapes, but it can be overcome with custom-made HA using CAD/CAM [37, 38].

As absorbable implants, PDLLA and PLGA are commonly used, especially in pediatric craniofacial surgery [39]. However, foreign body reaction and the weakness of materials such as screw fracture have been reported $[40,41]$. There are cases in which calcium phosphate implants have been used for the reconstruction of cranio-maxillofacial defects [42]. These printed calcium 
phosphate implants have good biocompatibility and suitable biodegradation and are similar to the mineral phase of the bone, so they do not cause artifacts or interference seen in other metallic alloplasts in CT or MRI. In addition, calcium phosphate implants show less mechanical performance than titanium but are suitable as a scaffold for bone tissue growth and can be loaded with bioactive protein or antibiotics.

\section{Workflow}

The modeling software used for 3D printing includes Mimics (Materialise, Leuven, Belgium), SolidWorks (Dassault Systemes, Velizy-Villacoublay, France), Amira (FEI Visualization Sciences Group, Merignac, France), Rhino (Robert McNeel \& Associates, Seattle, WA, USA), and SurgiCase CMF (Materialise, Leuven, Belgium). The printing software include ZPrinter and Projet (3D Systems, Rock Hill, SC, USA) and Alaris (Objet Limited, Rehovot, Israel) [12].

PSIs can be constructed through a manufacturing process and can also be produced by shaping directly from a 3D printing skull model [3]. In general, CT scan images are converted into two-dimensional (2D) digital imaging and communications in medicine (DICOM) files and converted to the 3D stereolithography (STL) format using CAD software $[1,8,43]$. The design methods for the reconstruction of the cranio-maxillofacial defects are as follows.

i) After printing the skull model of the pre-operative form, pre-bending of the plate, fabrication of an onlay template by model surgery, or fabrication of the implant on the skull model [44-48]

ii) After performing virtual surgery, including resection and reconstruction in the pre-operative image, printing of a resection guide or fabrication of the template by printing the skull model with virtual surgery $[49,50]$

iii) After printing of the skull model reconstructed symmetrically using a mirror image of the unaffected side, pre-bending of the plate, using it as a template, or fabrication of the implant directly on the skull model [51-53]

iv) After reconstruction symmetrically using a mirror image of the unaffected side and design of the 3D implant to fit precisely to the defect, fabrication of the PSI by transferring the PSI data to CAM software [3, 8, 32, 54-57]

\section{Future directions}

Digital workflows are time consuming and cannot be used for emergency procedures such as immediate posttraumatic surgery [10]. It takes from a few days to weeks to make the PSI outside the hospital [8]. However, with the development of 3D printers, relatively inexpensive personalized 3D printers have been introduced and the accuracy has increased, making it possible to manufacture products inside the hospital, reducing the time required. In addition, the development of professional CAD software familiar to surgeons and minimally invasive surgical procedures will provide predictable results.

\section{Conclusion}

By selecting the appropriate design method, manufacturing process, and implant material according to the case, it is possible to obtain a more accurate procedure, reduced surgical time, the prevention of various complications that can occur using the traditional method, and predictive results compared to the traditional method.

\section{Acknowledgements}

Not applicable.

Funding

Not applicable.

Availability of data and materials

The dataset supporting the conclusions of this article is included within the article.

Authors' contributions

The author wrote the manuscript and approved the final manuscript.

Ethics approval and consent to participate

Not applicable.

Consent for publication

Not applicable.

Competing interests

The author declares no competing interests.

\section{Publisher's Note}

Springer Nature remains neutral with regard to jurisdictional claims in published maps and institutional affiliations.

Received: 30 December 2017 Accepted: 16 January 2018

Published online: 05 February 2018

References

1. Rachmiel A, Shilo D, Blanc O, Emodi O (2017) Reconstruction of complex mandibular defects using integrated dental custom-made titanium implants. Br J Oral Maxillofac Surg 55:425-427

2. Kim JW, Kim DY, Ahn KM, Lee JH (2016) Surgical implications of anatomical variation in anterolateral thigh flaps for the reconstruction of oral and maxillofacial soft tissue defects: focus on perforators and pedicles. J Korean Assoc Oral Maxillofac Surg 42:265-270

3. Rudman K, Hoekzema C, Rhee J (2011) Computer-assisted innovations in craniofacial surgery. Facial Plast Surg 27:358-365

4. Seok H, Kim MK, Kim SG (2016) Reconstruction of partial maxillectomy defect with a buccal fat pad flap and application of 4-hexylresorcinol: a case report. J Korean Assoc Oral Maxillofac Surg 42:370-374

5. Groover MP, Zimmers EW (1984) CAD/CAM: computer-aided design and manufacturing. Prentice-Hall, Englewood Cliffs; London

6. Smith EH (2013) Mechanical engineer's reference book, 12th edn. Butterworth Heinemann, Oxford, England; Boston

7. Toth BA, Ellis DS, Stewart WB (1988) Computer-designed prostheses for orbitocranial reconstruction. Plast Reconstr Surg 81:315-324

8. Owusu JA, Boahene K (2015) Update of patient-specific maxillofacial implant Curr Opin Otolaryngol Head Neck Surg 23:261-264 
9. Levine JP, Patel A, Saadeh PB, Hirsch DL (2012) Computer-aided design and manufacturing in craniomaxillofacial surgery: the new state of the art. J Craniofac Surg 23:288-293

10. Peel S, Bhatia S, Eggbeer D, Morris DS, Hayhurst C (2017) Evolution of design considerations in complex craniofacial reconstruction using patient-specific implants. Proc Inst Mech Eng H 231:509-524

11. Kang SH, Kim MK, Lee JY (2016) Single-tooth dento-osseous osteotomy with a computer-aided design/computer-aided manufacturing surgical guide. J Korean Assoc Oral Maxillofac Surg 42:127-130

12. Jacobs CA, Lin AY (2017) A new classification of three-dimensional printing technologies: systematic review of three-dimensional printing for patientspecific craniomaxillofacial surgery. Plast Reconstr Surg 139:1211-1220

13. Lee YC, Sohn HB, Kim SK, Bae OY, Lee JH (2015) A novel method for the management of proximal segment using computer assisted simulation surgery: correct condyle head positioning and better proximal segment placement. Maxillofac Plast Reconstr Surg 37:21

14. Watson J, Hatamleh M, Alwahadni A, Srinivasan D (2014) Correction of facial and mandibular asymmetry using a computer aided design/computer aided manufacturing prefabricated titanium implant. J Craniofac Surg 25:1099-1101

15. Parthasarathy J (2014) 3D modeling, custom implants and its future perspectives in craniofacial surgery. Ann Maxillofac Surg 4:9-18

16. Gokuldoss PK, Kolla S, Eckert J (2017) Additive manufacturing processes: selective laser melting, electron beam melting and binder jetting-selection guidelines. Materials (Basel) 10:E672

17. Sidambe AT (2014) Biocompatibility of advanced manufactured titanium implants - a review. Materials (Basel) 7:8168-8188

18. Fina F, Goyanes A, Gaisford S, Basit AW (2017) Selective laser sintering (SLS) 3D printing of medicines. Int J Pharm 529:285-293

19. Otawa N, Sumida T, Kitagaki $\mathrm{H}$ et al (2015) Custom-made titanium devices as membranes for bone augmentation in implant treatment: modeling accuracy of titanium products constructed with selective laser melting. J Craniomaxillofac Surg 43:1289-1295

20. Bandyopadhyay A, Krishna BV, Xue W, Bose S (2009) Application of laser engineered net shaping (LENS) to manufacture porous and functionally graded structures for load bearing implants. J Mater Sci Mater Med 20(Suppl 1):S29-S34

21. Fafenrot S, Grimmelsmann N, Wortmann M, Ehrmann A (2017) Threedimensional (3D) printing of polymer-metal hybrid materials by fused deposition modeling. Materials (Basel) 10:E1199

22. Rubin JP, Yaremchuk MJ (1997) Complications and toxicities of implantable biomaterials used in facial reconstructive and aesthetic surgery: a comprehensive review of the literature. Plast Reconstr Surg 100:1336-1353

23. Zanotti B, Zingaretti N, Verlicchi A, Robiony M, Alfieri A, Parodi PC (2016) Cranioplasty: review of materials. J Craniofac Surg 27:2061-2072

24. Aydin S, Kucukyuruk B, Abuzayed B, Aydin S, Sanus GZ (2011) Cranioplasty: review of materials and techniques. J Neurosci Rural Pract 2:162-167

25. Acero J, Calderon J, Salmeron JI, Verdaguer JJ, Concejo C, Somacarrera ML (1999) The behaviour of titanium as a biomaterial: microscopy study of plates and surrounding tissues in facial osteosynthesis. J Craniomaxillofac Surg 27:117-123

26. Schipper J, Ridder GJ, Spetzger U, Teszler CB, Fradis M, Maier W (2004) Individual prefabricated titanium implants and titanium mesh in skull base reconstructive surgery. A report of cases. Eur Arch Otorhinolaryngol 261:282-290

27. Shah AM, Jung H, Skirboll S (2014) Materials used in cranioplasty: a history and analysis. Neurosurg Focus 36:E19

28. Ridwan-Pramana A, Wolff J, Raziei A, Ashton-James CE, Forouzanfar T (2015) Porous polyethylene implants in facial reconstruction: outcome and complications. J Craniomaxillofac Surg 43:1330-1334

29. Wellisz T (1993) Clinical experience with the Medpor porous polyethylene implant. Aesthet Plast Surg 17:339-344

30. Frodel $J$, Lee $S$ (1998) The use of high-density polyethylene implants in facial deformities. Arch Otolaryngol Head Neck Surg 124:1219-1223

31. Haq J, Patel N, Weimer K, Matthews NS (2014) Single stage treatment of ankylosis of the temporomandibular joint using patient-specific total joint replacement and virtual surgical planning. Br J Oral Maxillofac Surg 52:350-355

32. Kozakiewicz M, Szymor P (2013) Comparison of pre-bent titanium mesh versus polyethylene implants in patient specific orbital reconstructions. Head Face Med 9:32

33. Alonso-Rodriguez E, Cebrian JL, Nieto MJ, Del Castillo JL, Hernandez-Godoy J, Burgueno M (2015) Polyetheretherketone custom-made implants for craniofacial defects: report of 14 cases and review of the literature. J Craniomaxillofac Surg 43:1232-1238

34. O'Reilly EB, Barnett S, Madden C, Welch B, Mickey B, Rozen S (2015) Computedtomography modeled polyether ether ketone (PEEK) implants in revision cranioplasty. J Plast Reconstr Aesthet Surg 68:329-338

35. Tesavibul P, Chantaweroad S, Laohaprapanon A et al (2015) Biocompatibility of hydroxyapatite scaffolds processed by lithography-based additive manufacturing. Biomed Mater Eng 26:31-38

36. Garagiola U, Grigolato R, Soldo R et al (2016) Computer-aided design/computeraided manufacturing of hydroxyapatite scaffolds for bone reconstruction in jawbone atrophy: a systematic review and case report. Maxillofac Plast Reconstr Surg 38:2

37. Zhang L, Shen S, Yu H, Shen SG, Wang X (2015) Computer-aided design and computer-aided manufacturing hydroxyapatite/epoxide acrylate maleic compound construction for craniomaxillofacial bone defects. J Craniofac Surg 26:1477-1481

38. Figliuzzi M, Mangano FG, Fortunato L et al (2013) Vertical ridge augmentation of the atrophic posterior mandible with custom-made, computer-aided design/computer-aided manufacturing porous hydroxyapatite scaffolds. J Craniofac Surg 24:856-859

39. Essig H, Lindhorst D, Gander T et al (2017) Patient-specific biodegradable implant in pediatric craniofacial surgery. J Craniomaxillofac Surg 45:216-222

40. Xue AS, Koshy JC, Weathers WM et al (2014) Local foreign-body reaction to commercial biodegradable implants: an in vivo animal study. Craniomaxillofac Trauma Reconstr 7:27-34

41. Wiltfang J, Merten HA, Becker HJ, Luhr HG (1999) The resorbable miniplate system Lactosorb in a growing cranio-osteoplasty animal model. J Craniomaxillofac Surg 27:207-210

42. Klammert U, Gbureck U, Vorndran E, Rodiger J, Meyer-Marcotty P, Kubler AC (2010) 3D powder printed calcium phosphate implants for reconstruction of cranial and maxillofacial defects. J Craniomaxillofac Surg 38:565-570

43. Zhao L, Patel PK, Cohen M (2012) Application of virtual surgical planning with computer assisted design and manufacturing technology to craniomaxillofacial surgery. Arch Plast Surg 39:309-316

44. Danelson KA, Gordon ES, David LR, Stitzel JD (2009) Using a three dimensional model of the pediatric skull for pre-operative planning in the treatment of craniosynostosis-biomed 2009. Biomed Sci Instrum 45:358-363

45. Daniel M, Watson J, Hoskison E, Sama A (2011) Frontal sinus models and onlay templates in osteoplastic flap surgery. J Laryngol Otol 125:82-85

46. Hatamleh MM, Cartmill M, Watson J (2013) Management of extensive frontal cranioplasty defects. J Craniofac Surg 24:2018-2022

47. Azuma M, Yanagawa T, Ishibashi-Kanno N et al (2014) Mandibular reconstruction using plates prebent to fit rapid prototyping 3-dimensional printing models ameliorates contour deformity. Head Face Med 10:45

48. Lim CG, Campbell DI, Clucas DM (2014) Rapid prototyping technology in orbital floor reconstruction: application in three patients. Craniomaxillofac Trauma Reconstr 7:143-146

49. Liu YF, Xu LW, Zhu HY, Liu SS (2014) Technical procedures for templateguided surgery for mandibular reconstruction based on digital design and manufacturing. Biomed Eng Online 13:63

50. Soleman J, Thieringer F, Beinemann J, Kunz C, Guzman R (2015) Computerassisted virtual planning and surgical template fabrication for frontoorbital advancement. Neurosurg Focus 38:E5

51. Park SW, Choi JW, Koh KS, Oh TS (2015) Mirror-imaged rapid prototype skull model and pre-molded synthetic scaffold to achieve optimal orbital cavity reconstruction. J Oral Maxillofac Surg 73:1540-1553

52. Man QW, Jia J, Liu K, Chen G, Liu B (2015) Secondary reconstruction for mandibular osteoradionecrosis defect with fibula osteomyocutaneous flap flowthrough from radial forearm flap using stereolithographic 3-dimensional printing modeling technology. J Craniofac Surg 26:e190-e193

53. Yamada H, Nakaoka K, Horiuchi T et al (2014) Mandibular reconstruction using custom-made titanium mesh tray and particulate cancellous bone and marrow harvested from bilateral posterior ilia. J Plast Surg Hand Surg 48:183-190

54. Kim BJ, Hong KS, Park KJ, Park DH, Chung YG, Kang SH (2012) Customized cranioplasty implants using three-dimensional printers and polymethylmethacrylate casting. J Korean Neurosurg Soc 52:541-546

55. Li J, Hsu Y, Luo E, Khadka A, Hu J (2011) Computer-aided design and manufacturing and rapid prototyped nanoscale hydroxyapatite/polyamide (n-HA/PA) construction for condylar defect caused by mandibular angle ostectomy. Aesthet Plast Surg 35:636-640 
56. Rotaru H, Schumacher R, Kim SG, Dinu C (2015) Selective laser melted titanium implants: a new technique for the reconstruction of extensive zygomatic complex defects. Maxillofac Plast Reconstr Surg 37:1

57. Jo YY, Kim SG, Kim MK, Shin SH, Ahn J, Seok H (2017) Mandibular reconstruction using a customized three-dimensional titanium implant applied on the lingual surface of the mandible. J Craniofac Surg. https://doi.org/10.1097/ SCS.0000000000004119

Submit your manuscript to a SpringerOpen ${ }^{\odot}$ journal and benefit from:

- Convenient online submission

- Rigorous peer review

- Open access: articles freely available online

- High visibility within the field

- Retaining the copyright to your article

Submit your next manuscript at $\boldsymbol{\sim}$ springeropen.com 